\title{
COMPORTAMENTO FISIOLÓGICO DE SEMENTES DE PITOMBEIRA [Talisia esculenta (A. ST. Hil) Radlk] SUBMETIDAS À DESIDRATAÇÃ̃ ${ }^{1}$
}

\author{
EDNAURSULINO ALVES ${ }^{2,6}$, KELINA BERNARDO SILVA $^{3}$, RISELANE DE LUCENAALCÂNTARA BRUNO², \\ ANARLETE URSULINO ALVES ${ }^{3}$, EDSON DE ALMEIDA CARDOSO $^{4}$, EDILMAPEREIRA GONÇALVES $^{5}$ \\ MARIA DO SOCORRO SOUTO BRAZ ${ }^{3}$
}

RESUMO - Em condições normais, as sementes de pitombeira [Talisia esculenta (A. St. Hil) Radlk] perdem a qualidade fisiológica rapidamente, o que dificulta sua utilização pelos viveiristas. Em função da escassez de pesquisas referentes à dessecação de suas sementes, o trabalho teve como objetivo avaliar a qualidade fisiológica de sementes de pitombeira submetidas a cinco períodos de secagem $(0 ; 24 ; 48 ; 96$ e 120 horas). O delineamento experimental foi inteiramente ao acaso, e os dados, submetidos à análise de variância e de regressão polinomial. A avaliação do efeito dos tratamentos foi realizada através da determinação do teor de água, porcentagem de germinação e testes de vigor (primeira contagem, índice de velocidade e tempo médio para germinação, comprimento e massa da matéria seca da raiz primária e parte aérea). Verificou-se um teor de água inicial de $40 \%$, o qual foi reduzindo com os períodos de secagem; conseqüentemente, registraram-se as maiores porcentagens de germinação (99\%) com 53 horas de secagem. Quanto ao vigor, os maiores valores de primeira contagem $(78 \%)$ e comprimento da parte aérea $(11,29 \mathrm{~cm})$ foram obtidos com 38 horas de secagem; já o menor tempo médio para germinação (17 dias) e comprimento máximo da raiz primária $(15,79 \mathrm{~cm})$ ocorreram quando a secagem foi por 40 horas. Quanto ao índice de velocidades de germinação $(1,41)$, massa da matéria seca das raízes $(0,079)$ e parte aérea $(0,229)$, os valores máximos foram obtidos quando as sementes foram submetidas à secagem por 44; 33 e 50 horas, respectivamente. Diante dos resultados, recomenda-se a secagem de sementes de pitombeira por até 48 horas, como forma de garantir a germinação e o vigor. Termos para indexação: propagação, germinação, vigor, frutífera nativa, fruticultura.

\section{PHYSIOLOGICAL PERFORMANCE OF PITOMBEIRA [Talisia esculenta (A. ST. Hil) Radlk] SEEDS SUBMITTED TO DEHYDRATION}

\begin{abstract}
In normal conditions, pitombeira seeds [Talisia esculenta (St. Hil) Radlk] quickly lose their physiological quality. This makes it difficult for cultivators to use them. Research on pitombeira seed desiccation is scarce. Therefore, this work aimed to evaluate the physiological quality of pitombeira seeds submitted to five drying periods $(0,24,48,96$ e 120 hours). The experimental design was entirely randomized and the data was submitted to the variance analysis and polynomial regression. The treatment effect evaluation was accomplished by means of the determination of the water content, germination percentage and vigor tests (first count, speed index and average germination time, primary root and aerial leaves length and dry mass). The initial water content of $40 \%$ was increasingly reducing within drying time. Consequently, the largest germination percentages (99\%) were observed within 53 hours of drying. In relation to the vigor, the largest first count values $(78 \%)$ and aerial part length $(11.29 \mathrm{~cm})$ were obtained within 38 hours of drying. On the other hand, the shortest average germination time (17 days) and maximum primary root length $(15.79 \mathrm{~cm})$ occurred with 40 hours of drying. Concerning the germination velocity index (1.41), root dry mass (0.079) and aerial part (0.229), the maximum values were obtained when the seeds were submitted to drying 44, 33 and 50 hours, respectively. The results confirm that the recommended drying time for pitombeira seeds is up to 48 hours to guarantee germination and vigor.
\end{abstract}

Index Terms: propagation, germination, vigor, native fruit tree, fruticulture.

\section{INTRODUÇÃO}

O Brasil possui considerável área de mata nativa com grande diversidade de árvores frutíferas ainda pouco estudadas; muitas com potencial de aproveitamento pouco explorado e com falta de estudos que permitam a implantação de pomares comerciais (Kohama et al., 2006).

A pitombeira, planta frutífera da família das Sapindáceas, desenvolve-se tanto no interior da mata primária densa como em formações secundárias, porém sempre em várzeas aluviais e fundos de vales dos ecossistemas de Cerrado, Mata Atlântica e Floresta Amazônica. Os frutos, de polpa carnosa e adocicada, são popularmente apreciados nas regiões Norte e Nordeste do País, sendo consumidos in natura. A madeira vem sendo utilizada para obras internas na construção civil, como forros, molduras, tábuas para assoalho, na carpintaria e para confecção de caixas. Sua propagação é por via sexuada, através de sementes, as quais apresentam curta longevidade, sendo necessária a semeadura logo após a extração dos frutos; é também considerada recalcitrante, ou seja, a redução da umidade pode ocasionar danos, prejudicando sua viabilidade e vigor, resultando até em

(Trabalho 061-07). Recebido em:15-03-2007. Aceito para publicação em: 10-04-2008.

${ }^{2}$ Professoras do Departamento de Fitotecnia. CCA-UFPB, Areia-PB.

${ }^{3}$ Alunas do Programa de Pós-Graduação em Agronomia. CCA-UFPB, Areia-PB.

${ }^{4}$ Aluno do Curso de Graduação em Agronomia. CCA-UFPB, Areia-PB; Bolsista PIBIC-CNPq

${ }^{5}$ Bolsista PRODOC-CAPES do CCA-UFPB, Areia-PB.

${ }^{6}$ Autora para correspondência. Caixa Postal 02, CEP: 58.397-000, Areia-PB, e-mail: ednaursulino@cca.ufpb.br 
sua morte (Lorenzi, 2002).

A qualidade inicial das sementes, entendida como intrínseca por ocasião de sua colheita, deve ser preservada tanto quanto possível, até que sejam utilizadas para semeadura (Carneiro \& Aguiar, 1993). A preservação da qualidade fisiológica das sementes é fundamental para a manutenção dos bancos de germoplasma e no processo de repovoamento da vegetação em áreas degradadas, pois permite o uso de espécies vegetais em épocas e locais diferentes aos de sua origem (Kohama et al., 2006).

Diversas técnicas são, com freqüência, estudadas em busca de melhores condições de armazenamento, sendo que a principal técnica de conservação de sementes durante o armazenamento é, ainda, a redução do seu metabolismo, seja através da remoção da água, seja da diminuição da temperatura. Contudo, várias espécies tropicais, principalmente arbóreas nativas do Brasil, são intolerantes à dessecação aos níveis desejáveis ao armazenamento, o que requer o desenvolvimento de tecnologias específicas para sua conservação (Kohama et al., 2006).

A água assume importante papel no período de formação e maturação das sementes e, ao final da maturação, dois tipos de comportamento são observados: nas sementes ortodoxas, há redução considerável do teor de água e, nas recalcitrantes, mantém-se o elevado teor de água (Barbedo \& Marcos-Filho, 1998).

A habilidade das sementes ortodoxas de tolerarem a dessecação é adquirida progressivamente durante o desenvolvimento, antes que as sementes sofram severa queda no seu conteúdo de água. Porém, não se pode afirmar se a tolerância é adquirida antes ou em resposta à perda de água (Leprince et al., 1993). Ainda segundo os autores, existem sementes que apresentam rápida transição de uma fase de intolerância à tolerância à dessecação, enquanto outras (recalcitrantes) não podem resistir à dessecação, devendo seu conteúdo de água permanecer alto durante todo o seu desenvolvimento e armazenamento.

Segundo Roberts (1973), as sementes recalcitrantes não sofrem secagem natural na planta-matriz e são liberadas com elevado teor de água e, se for reduzido a um nível considerado crítico, geralmente elevado, ocorrerá a perda rápida da viabilidade, podendo levar até a morte. Porém, existe outro grupo de espécies para as quais não se aplica a regra geral de redução da temperatura e teor de água no armazenamento e cujo período de viabilidade é bem mais reduzido.

As espécies recalcitrantes que possuem menores períodos de viabilidade são originárias de regiões tropicais úmidas, onde existe um ambiente adequado, aproximadamente constante ao longo do ano, para a germinação de suas sementes, que geralmente não apresentam dormência. Por outro lado, as espécies recalcitrantes provenientes de regiões temperadas, freqüentemente, possuem algum tipo de dormência, na maioria das vezes relacionada com exigência em frio. Essa característica permite-lhes permanecerem viáveis até que as condições adversas acabem. A maioria das frutíferas tropicais perenes, economicamente importantes, é recalcitrante (Chin \& Roberts,
1980). Dentre elas, podem ser citadas a Mangifera indica L. (Fu et al., 1990), Theobroma cacao L. (Zink \& Rochelle, 1994); além destas, estudos têm demonstrado o comportamento recalcitrante de outras espécies, como Myrciaria cauliflora (Mart.) O.Berg. (Valio \& Ferreira, 1992), Hancornia speciosa Gomes (Parente \& Carmona, 1988), Myrciaria dubia (H.B.K.) McVaugh (Ferreira \& Gentil, 2003), Campomanesia adamantium Camb. (Melchior et al., 2006), Eugenia brasiliensis Lam., E. cerasiflora Miq., E. involucrata DC., E. pyriformis Camb., E. umbelliflora Berg. e E. uniflora L. (Delgado \& Barbedo, 2007).

Apesar da importância das espécies que apresentam sementes recalcitrantes, não há estudos científicos que avaliem seu grau de sensibilidade à dessecação. Além de apresentarem curta longevidade, sendo necessário o semeio logo após a extração dos frutos, é também considerada recalcitrante, ou seja, a redução da umidade pode ocasionar danos, prejudicando sua viabilidade e vigor, resultando até em sua morte. Em sementes recalcitrantes, a água subcelular está fortemente associada às superfícies macromoleculares, assegurando, em parte, a estabilidade de membranas e macromoléculas (Bovi et al., 2004). A perda de água estrutural durante o processo de secagem pode causar alteração de sistemas metabólicos e de membranas, resultando no início do processo de deterioração (Farrant et al., 1988). Já a viabilidade dessas sementes é reduzida quando o teor de água atinge valores inferiores àqueles considerados críticos; quando iguais ou inferiores àqueles considerados letais, há perda total da viabilidade (Hong \& Ellis, 1992). A sensibilidade das sementes recalcitrantes à dessecação depende da espécie, sendo os teores crítico e letal de água relativamente altos, respectivamente, de 27 a $38 \%$ e de 12 a $22 \%$ para sementes de Euterpe edulis Mart. (Andrade \& Pereira, 1997).

Diversas espécies arbóreas nativas, com grande potencial de utilização na arborização urbana e reflorestamentos, têm seu uso limitado em função da carência de informações técnicas sobre o manejo de suas sementes, como é o caso de algumas espécies, tais como as cerejeiras, pitangueiras, grumixameiras, uvaieiras, pitombeiras, entre outras (Barbedo et al., 1998).

Dessa forma, o presente trabalho teve como objetivo verificar o efeito de diferentes períodos de secagem, sobre a emergência de plântulas e o vigor de sementes de pitombeira.

\section{MATERIAL E MÉTODOS}

A pesquisa foi conduzida no Laboratório de Análise de Sementes do Centro de Ciências Agrárias da Universidade Federal da Paraíba, em Areia - PB, com frutos de pitombeira (Talisia esculenta), de coloração marrom-escura, colhidos diretamente de árvores nativas localizadas no município de Areia, no Estado da Paraíba. Após a colheita, os frutos foram transportados ao laboratório, onde as sementes foram extraídas manualmente, submetidas à fermentação por quatro dias e lavagem em água corrente para a retirada do arilo.

Após esses procedimentos, quatro repetições de 25 sementes foram retiradas e semeadas imediatamente (período zero, denominada controle sem secagem), e o restante foi colocado sobre papel toalha e submetido à secagem à sombra 
por 24; 48; 72; 96 e 120 horas em ambiente de laboratório com temperatura e umidade relativa do ar em torno de $27^{\circ} \mathrm{C}$ e $45 \%$, respectivamente. Nos intervalos preestabelecidos, amostras de sementes foram retiradas do lote inicial para a realização dos testes descritos a seguir:

Teor de água: para sua determinação, foram utilizadas quatro repetições com 10 sementes cada, sendo utilizado o método da estufa a $105 \pm 3^{\circ} \mathrm{C}$, durante 24 horas (Brasil, 1992), cujos resultados foram expressos em porcentagem, em base úmida.

Emergência de plântulas: no teste de emergência, em condições de casa de vegetação, foram utilizadas quatro repetições de 25 sementes, sendo essas semeadas em bandejas de plástico com dimensões de $45 \times 30 \times 7 \mathrm{~cm}$, contendo areia lavada e esterilizada em autoclave, e a umidade do substrato foi mantida através de irrigações diárias por meio de um regador manual. As avaliações foram realizadas no $35^{\circ}$ dia após a instalação do teste, cujo critério utilizado foi o de plântulas normais que apresentavam a parte aérea acima do nível do substrato (Brasil, 1992), e os resultados, expressos em porcentagem.

Índice de velocidade de emergência de plântulas (IVE): calculado de acordo com a fórmula proposta por Maguire (1962), foi baseado na leitura diária do número de plântulas emergidas, a partir do $15^{\circ}$ até o $35^{\circ}$ dia após a instalação do teste.

Comprimento de plântulas: realizado ao final do teste de emergência em casa de vegetação, onde o comprimento da raiz primária e da parte aérea das plântulas normais foi medido com o auxílio de uma régua graduada em centímetros, sendo os resultados expressos em centímetros por plântula.

Massa da matéria seca de plântulas: também realizado ao final do teste de emergência em casa de vegetação, onde as raízes e a parte aérea das plântulas normais foram colocadas em sacos de papel e levados para estufa com circulação forçada de ar, a $65{ }^{\circ} \mathrm{C}$, permanecendo até atingir peso constante. Os resultados foram expressos em gramas por plântula, conforme recomendações de Nakagawa (1999).

Tempo médio e freqüência relativa de emergência: $o$ tempo médio e a freqüência relativa de emergência foram calculados conforme fórmulas citadas por Labouriau \& Valadares (1976) e Labouriau (1983):

Tempo médio de emergência: $\mathrm{t}=\frac{\sum n i t i}{\sum n i}$, onde: $\mathrm{t}=$ tempo médio de emergência; $\mathrm{ni}=$ número de sementes germinadas por dia; $\mathrm{ti}$ = tempo de incubação (dias).

Freqüência relativa de emergência: $\mathrm{Fr}=\left(\frac{n i}{\sum n i}\right) \times 100 \quad ; \mathrm{em}$ que $\mathrm{ni}=$ número de sementes germinadas por dia; $\sum$ ni $=$ número total de sementes germinadas.

O delineamento experimental utilizado foi o inteiramente ao acaso, e os resultados foram submetidos à análise de variância e de regressão polinomial, onde foram testados os modelos linear, quadrático e cúbico, e selecionou-se, para explicar os dados, aquele significativo e com maior coeficiente de determinação $\left(R^{2}\right)$.

\section{RESULTADOS E DISCUSSÃO}

Pelos dados da Figura 1, observa-se a relação entre o teor de água das sementes e o tempo de secagem. O processo de secagem adotado pode ser classificado como lento (Pammenter et al., 1998), pois demandou 120 horas para que o teor de água inicial das sementes (40\%) baixasse para $37 \%$. A desidratação progressiva não prejudicou a emergência de plântulas, no entanto reduziu bastante o vigor. Assim, observou-se que o teor de água das sementes, inicialmente em torno de $40 \%$, reduziu linearmente com os períodos de secagem (Figura 1). Este teor inicial de água situa-se abaixo dos verificados em sementes recalcitrantes de algumas espécies de Eugenia nativas do Brasil, tais como 67\% para E. pyriformis (Andrade \& Ferreira, 2000), 47-53\% para E. dysenterica DC. (Andrade et al., 2003), 63\% para E. involucrata (Maluf et al., 2003) e 43\% para E. rostrifolia Legr. (Santos et al., 2004).

A secagem lenta não é adequada para sementes recalcitrantes e pode provocar danos à estrutura das membranas (Pammenter \& Berjak, 1999). Porém, independentemente do tempo de desidratação, as sementes recalcitrantes não sobrevivem quando dessecadas abaixo de certos limites, em geral mais elevados que os observados para a sobrevivência de espécies ortodoxas (Marcos Filho, 2005).

Quanto à emergência de plântulas, os maiores valores (99\%) foram obtidos após secagem das sementes por 52,95 horas. Após esse período registrou-se redução na porcentagem de emergência de plântulas (Figura 2), o que está de acordo com Farrant et al. (1988), quando relataram que a perda de água estrutural durante o processo de secagem de sementes recalcitrantes pode causar severas alterações dos sistemas metabólicos e de membranas, dando início ao processo de deterioração dessas sementes. Martins et al. (1999) também comentaram que, abaixo de uma faixa de teor de água situada entre 40,7 e 51,4 \%, os valores de germinação de sementes de Euterpe espiritosantensis Fernandes foram significativamente reduzidos.

Sementes de algumas espécies brasileiras de Eugenia, como as de E. involucrata (Barbedo et al., 1998; Maluf et al., 2003), E. dysenterica (Andrade et al., 2003), E. stipitata ssp. sororia (Gentil e Ferreira, 1999) e de E. brasiliensis Lam. (Kohama et al., 2006), apresentam-se sensíveis à secagem, ao sofrerem reduções entre 5 e $12 \%$ no seu teor de água. Resultados diferentes foram obtidos por Schmildt et al. (1993) com sementes de mamão, onde a redução do teor de água para 9,1 e 10,6 \%, por meio de secagem ao sol, por três dias, e à sombra por sete, respectivamente, não influenciou em sua germinação.

Com relação ao vigor, verificou-se que o mesmo reduziu significativamente com os períodos de secagem. Na primeira contagem de germinação, os valores máximos (78\%) ocorreram no período de 38 horas de secagem (Figura 3). Já para o índice de velocidade de germinação (Figura 4), os maiores valores $(1,41)$ foram obtidos com 44 horas, enquanto o menor tempo médio para germinação (17 dias) foi registrado com secagem por 40 horas (Figura 5).

Ainda com relação ao vigor, observou-se que o 
comprimento máximo da raiz primária $(15,79 \mathrm{~cm})$ e da parte aérea $(11,29 \mathrm{~cm})$ foi alcançado quando o período de secagem foi de 40 e 38 horas, respectivamente (Figuras 6 e 7). Em relação à massa da matéria seca das raízes (Figura 8$)$, o valor máximo $(0,079 \mathrm{~g})$ foi obtido com 33 horas de secagem, enquanto da parte aérea $(0,229 \mathrm{~g})$ foi com 50 horas (Figura 9).

De forma geral, a maior parte dos testes de vigor utilizados indicou que a secagem por períodos superiores a 48 horas tiveram efeito prejudicial no vigor das sementes (Fig.3), indicando que as mesmas são sensíveis à dessecação, uma vez que períodos prolongados de secagem causaram efeitos fisiológicos prejudiciais. Diante dos resultados, constatou-se que os testes de vigor foram eficientes em detectar mudanças degenerativas nas sementes, não reveladas pela germinação.

Embora a emergência das plântulas de pitombeira não tenha sofrido grande redução com os períodos de secagem, os resultados dos testes de vigor evidenciaram que a qualidade fisiológica das mesmas foi significativamente prejudicada a partir do terceiro nível (Tabela 3), ou seja, ao reduzir o teor de água de 40,23 para 39,41\%. Dessa forma, pode-se considerar que o teor de água crítico seja superior a $39 \%$ para sementes de pitombeira que, segundo observações em sementes de espécies arbóreas tropicais brasileiras (Bilia et al., 1999; Andrade, 2001; Maluf et al., 2003), estaria situado entre os mais elevados.

A sensibilidade das sementes recalcitrantes à dessecação depende da espécie, sendo os teores de água crítico (27 a 38\%) e letal (12 a 22\%) relativamente altos (Andrade \& Pereira 1997). Delgado (2006) também não constatou redução na germinação de sementes de pitanga (E. uniflora L.) durante a desidratação, no entanto o vigor começou a ser reduzido quando o teor de água atingiu valores inferiores a 42,6\% (teor crítico de água), e as sementes perderam a viabilidade quando o teor de água atingiu valores inferiores a $32,5 \%$. No caso das sementes de pitombeira, os períodos de secagem não prejudicaram a emergência das plântulas, no entanto o vigor das sementes foi reduzido drasticamente.

De acordo com os dados da Figura 10, observam-se vários polígonos de freqüência relativa de germinação de sementes de pitombeira que diferem quanto ao número, posição e freqüência das modas. Nos períodos de secagem por 24 e 48 horas, tem-se uma germinação mais rápida e uniforme, enquanto nos demais períodos (zero, 72; 96 e 120) houve uma grande desuniformidade na germinação das sementes.

Nos períodos de secagem por zero, 24 e 48 horas, o deslocamento do tempo médio de germinação foi para a direita da moda principal, revelando que a heterogeneidade das sementes em relação à sua taxa de germinação foi causada por uma minoria de sementes que germinam lentamente, e não por poucas que germinam rapidamente. Nos demais períodos, o deslocamento do tempo médio foi para a esquerda da moda principal, indicando que grande parte das sementes germinou lentamente. Dessa forma, fica evidente a importância da secagem por períodos adequados para a manutenção do vigor das sementes, uma vez que aquelas mais vigorosas proporcionarão rápida e uniforme emergência de plântulas, o que facilitará a produção de mudas.

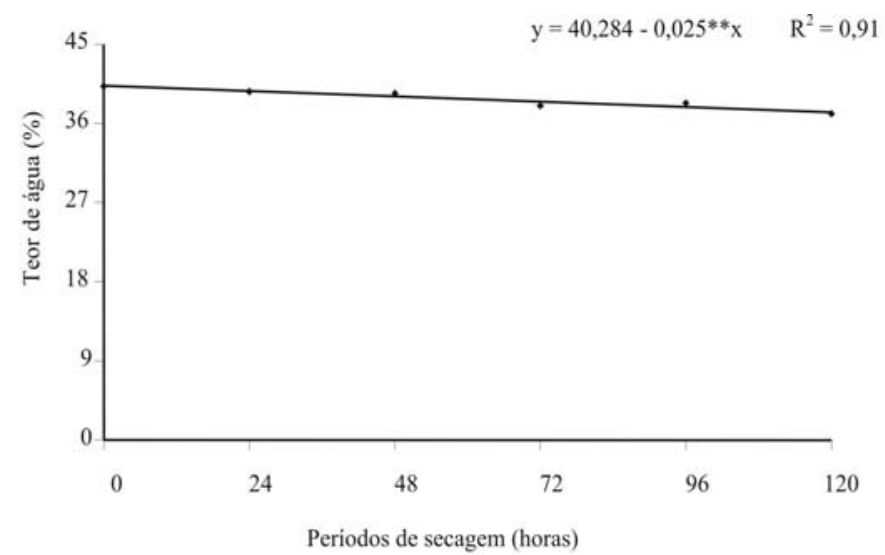

FIGURA 1- Teor de água de sementes de pitombeira em função de diferentes períodos de secagem. CCA-UFPB, Areia-PB, fevereiro/2007.

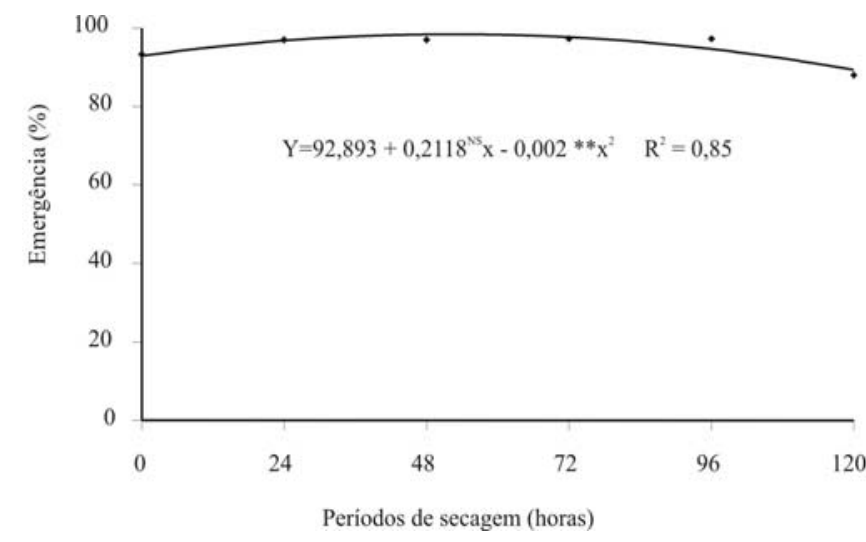

FIGURA 2 - Porcentagem de emergência de plântulas de pitombeira, oriundas de sementes submetidas a diferentes períodos de secagem. CCA-UFPB, Areia-PB, fevereiro/2007.

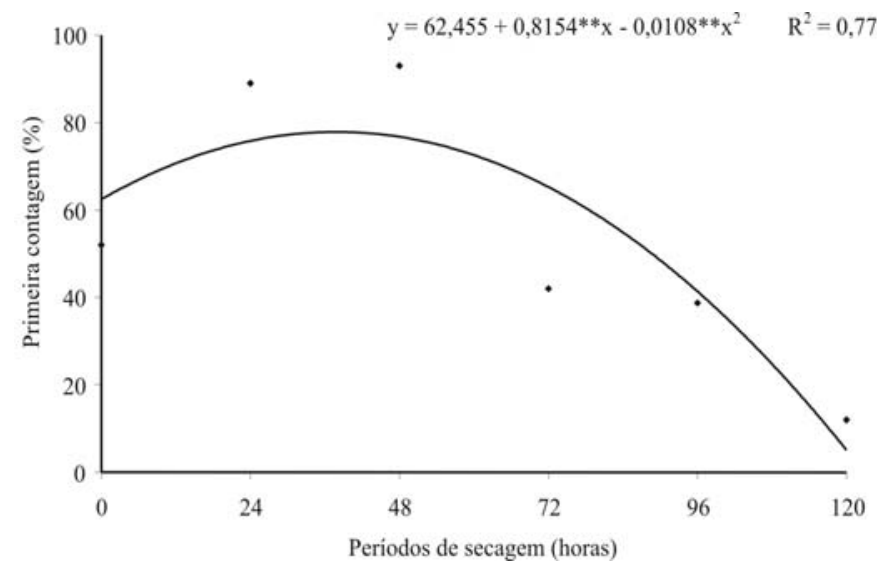

FIGURA 3 - Primeira contagem de emergência de plântulas de pitombeira, oriundas de sementes submetidas a diferentes períodos de secagem. CCA-UFPB, Areia-PB, fevereiro/2007. 


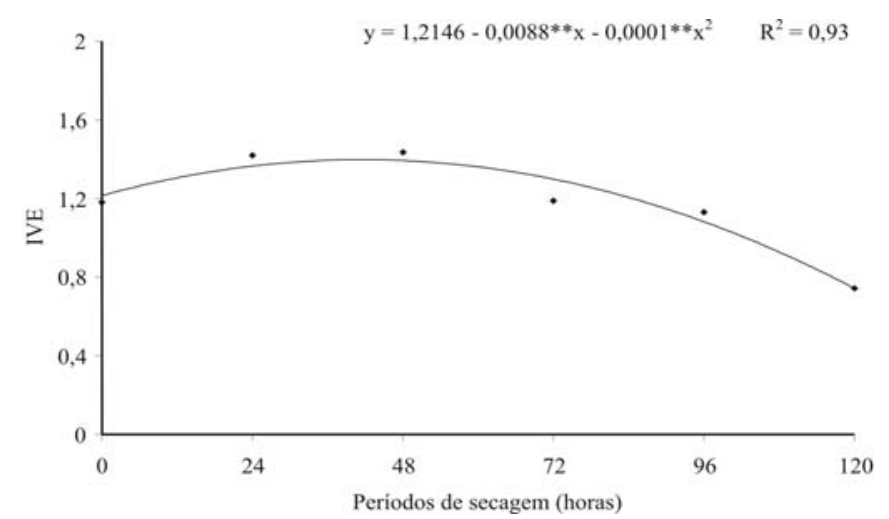

FIGURA 4- Índice de velocidade de emergência de plântulas de pitombeira, oriundas de sementes submetidas a diferentes períodos de secagem. CCA-UFPB, Areia$\mathrm{PB}$, fevereiro/2007.

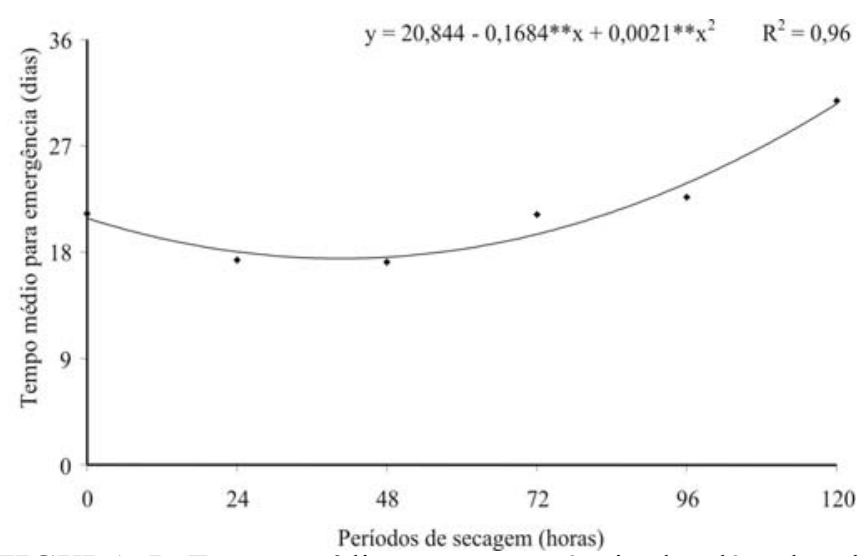

FIGURA 5 -Tempo médio para emergência de plântulas de pitombeira, oriundas de sementes submetidas a diferentes períodos de secagem. CCA-UFPB, Areia-PB, fevereiro/2007.

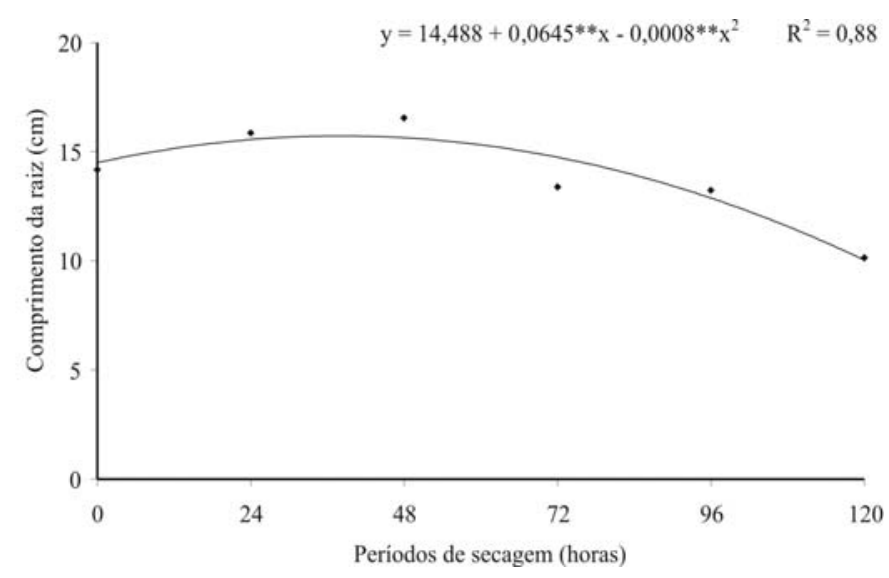

FIGURA 6 - Comprimento da raiz principal de plântulas de pitombeira, oriundas de sementes submetidas a diferentes períodos de secagem. CCA-UFPB, Areia$\mathrm{PB}$, fevereiro/2007.

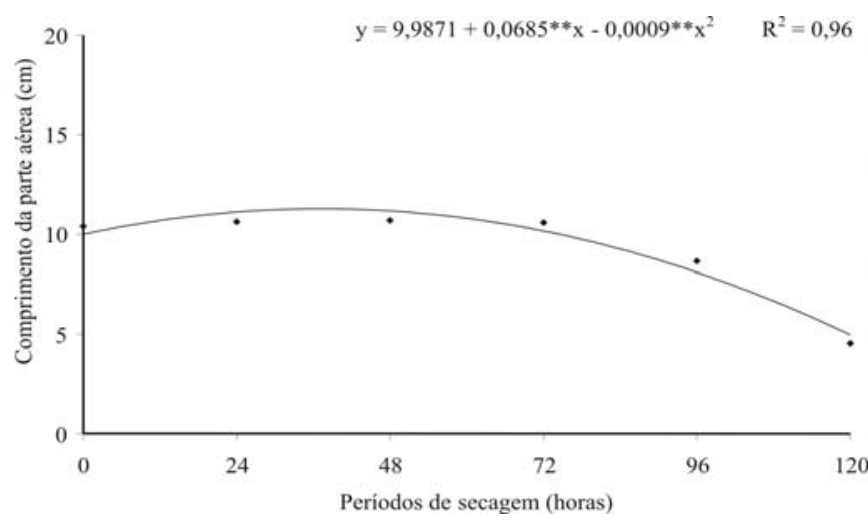

FIGURA 7- Comprimento da parte aérea de plântulas de pitombeira, oriundas de sementes submetidas a diferentes períodos de secagem. CCA-UFPB, Areia-PB, fevereiro/2007.

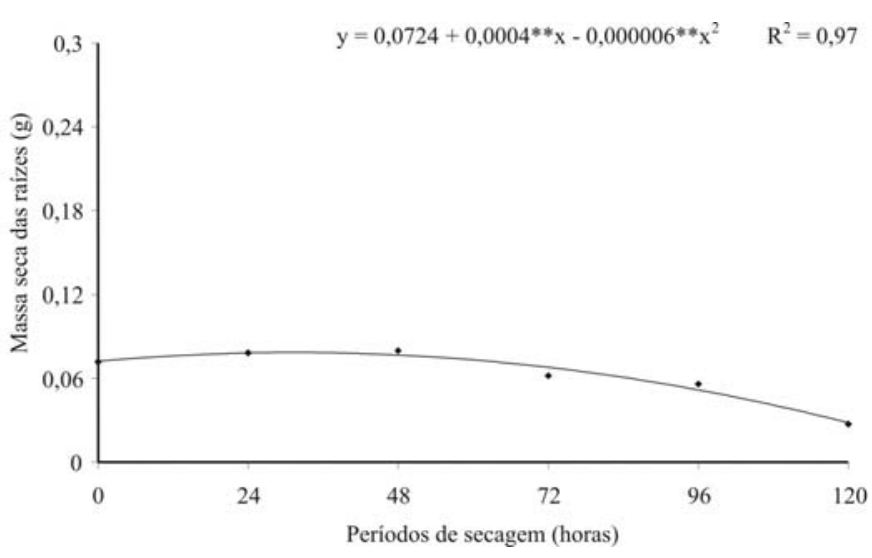

FIGURA 8 - Massa da matéria seca das raízes de plântulas de pitombeira, oriundas de sementes submetidas a diferentes períodos de secagem. CCA-UFPB, Areia$\mathrm{PB}$, fevereiro/2007.

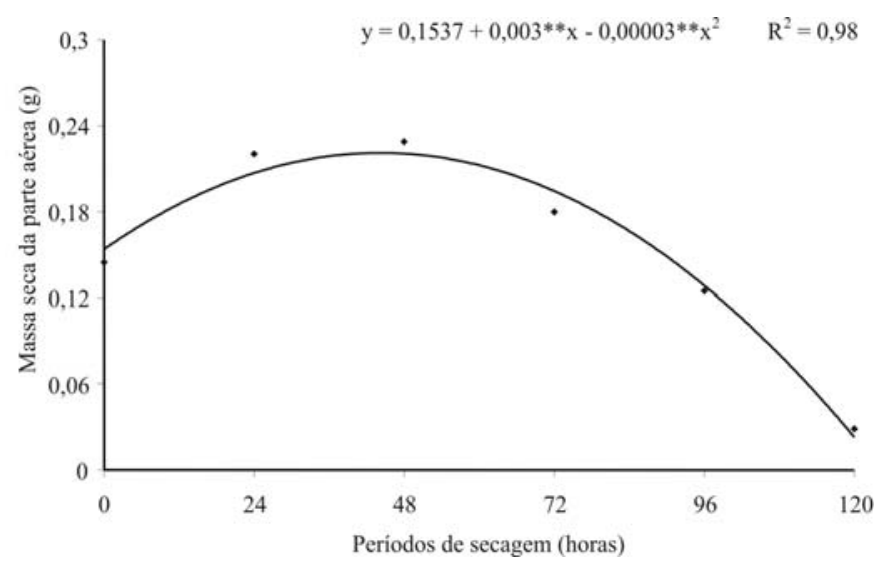

FIGURA 9 - Massa da matéria seca da parte aérea de plântulas de pitombeira, oriundas de sementes submetidas a diferentes períodos de secagem. CCA-UFPB, Areia-PB, fevereiro/2007. 


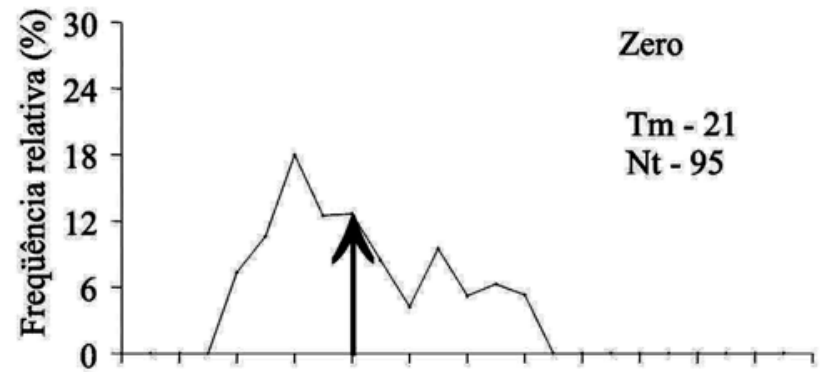

$\begin{array}{lllllllllllll}13 & 15 & 17 & 19 & 21 & 23 & 25 & 27 & 29 & 31 & 33 & 35 & 37\end{array}$ Dias de germinação
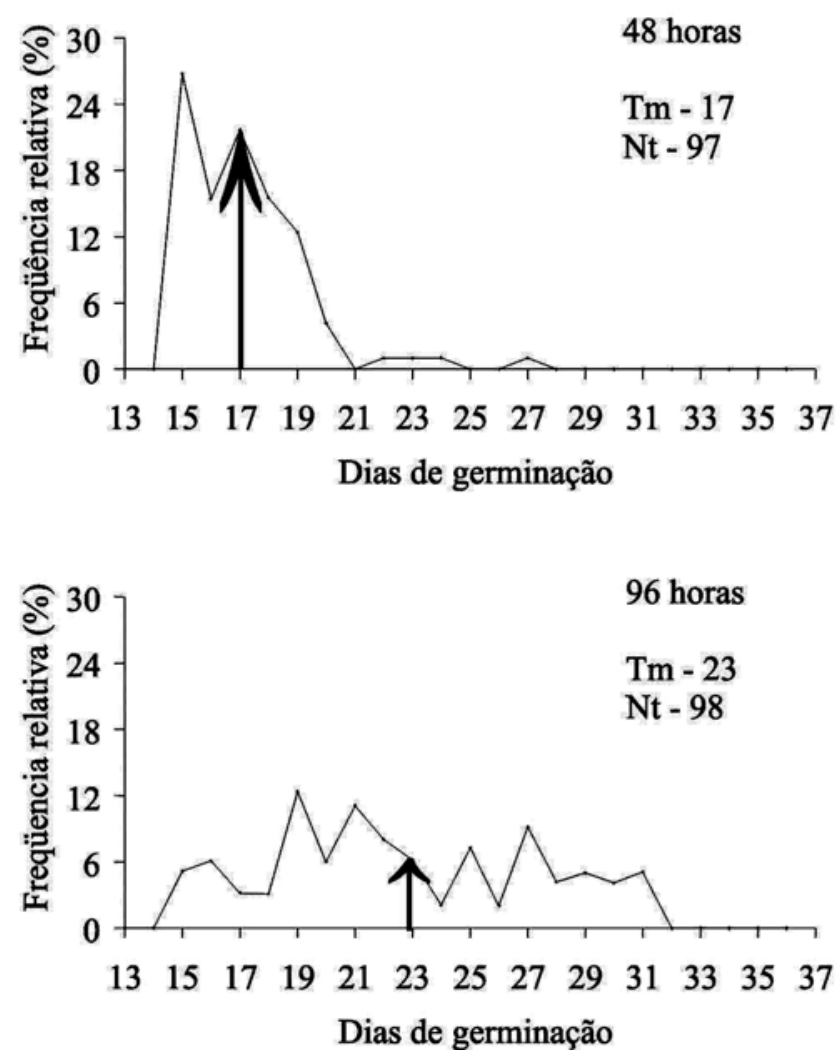
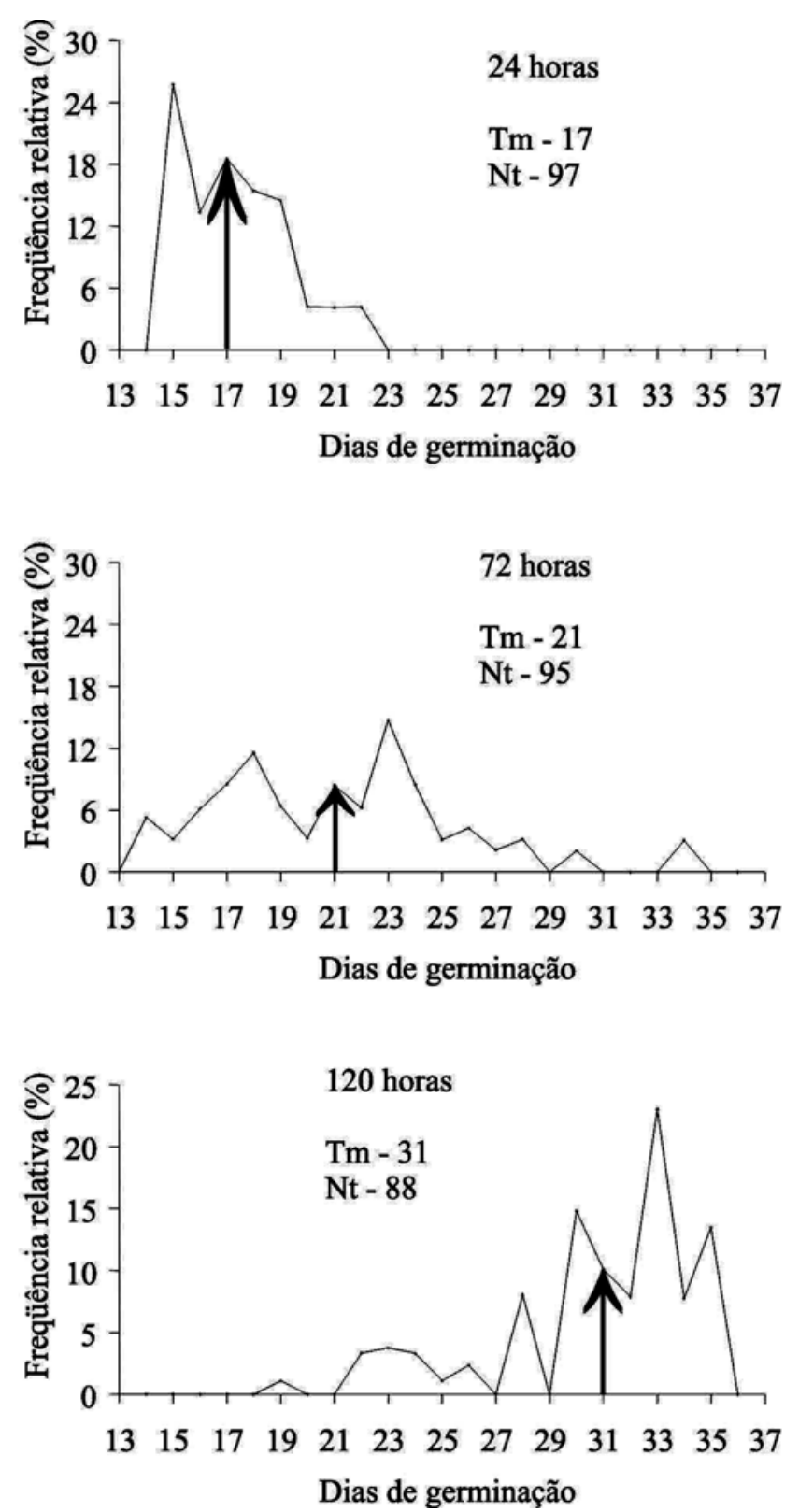

FIGURA 10 - Freqüência relativa da emergência de plântulas de pitombeira, oriundas de sementes submetidas a diferentes períodos de secagem. $(\mathrm{Nt}=$ número total de sementes germinadas, e $\mathrm{Tm}=$ tempo médio de emergência). CCA-UFPB, Areia-PB, fevereiro/2007.

\section{CONCLUSÃO}

Para a manutenção da emergência de plântulas e vigor das sementes de pitombeira, a secagem deve ser feita por até 48 horas, quando se obtêm $39,9 \%$ de teor de água.

\section{REFERÊNCIAS}

ANDRADE, A.C.S. The effect of moisture content and temperature on the longevity of heart of palm seeds (Euterpe edulis Mart.). Seed Science and Technology, Zürich, v.29, n.1, p.171-182,2001.

ANDRADE, A.C.S.; CUNHA, R.; SOUZA, A.F.; REIS, R.B.; ALMEIDA, K.J. Physiological and morphological aspects of seed viability of a neotropical savannah tree, Eugenia dysenterica 
DC. Seed Science and Technology, Zurich, v.31, n.1, p.125-137, 2003.

ANDRADE, A.C.S.; PEREIRA, T.S. Comportamento de armazenamento de sementes de palmiteiro (Euterpe edulis Mart.). Pesquisa Agropecuária Brasileira, Brasília, v.32, n.10, p.987991, 1997.

ANDRADE. R.N.B.; FERREIRA, A.G. Germinação e armazenamento de sementes de uvaia (Eugenia pyriformis Camb.) - Myrtaceae. Revista Brasileira de Sementes, Brasília, v.22, n.2, p.118-125, 2000

BARBEDO, C.J.; KOHAMA, S.; MALUF, A.M.; BILIA, D.A.C. Germinação e armazenamento de diásporos de cerejeira (Eugenia involucrata DC - Myrtaceae) em função do teor de água. Revista Brasileira de Sementes, Brasília, v.20, n.1, p.184-188, 1998.

BARBEDO, C.J.; MARCOS-FILHO, J. Tolerância à dessecação de sementes. Acta Botanica Brasilica, São Paulo, v.12, n.2, p.145164,1998

BILIA, D.A.C.; MARCOS FILHO, J.; NOVEMBRE, A.D.L.C. Desiccation tolerance and seed storability of Inga uruguensis Hook. et Arn. Seed Science and Technology, Zürich, v.27, n.1, p.77-89, 1999.

BOVI, M.L.A.; MARTINS, C.C.; SPIERING, S.H. Desidratação de sementes de quatro lotes de pupunheira: efeitos sobre a germinação e o vigor. Horticultura Brasileira, Brasília, v.22, n.1, p.109-112, 2004

BRASIL. Ministério da Agricultura, do Abastecimento e da Reforma Agrária. Regras para análise de sementes. Brasília: SNAD/DNDV/CLAV, 1992.365p.

CARNEIRO, J.G.A.; AGUIAR, I.B. Armazenamento de sementes. In: AGUIAR, I.B.; PIÑA-RODRIGUES, F.C.M.; FIGLIOLIA, M.B. (Ed.). Sementes florestais tropicais. Brasília: ABRATES, 1993. p.333-350.

CHIN, H.F.; ROBERTS, E.H. Recalcitrant crop seed. Malaysia: Tropical Press SND, 1980. 152p.

DELGADO, L.F. Tolerância à dessecação em sementes de espécies brasileiras de Eugenia. 2006. 96 f. Dissertação (Mestrado em Biodiversidade Vegetal e Meio Ambiente) Instituto de Botânica da Secretaria do Meio Ambiente, São Paulo, 2006.

DELGADO, L.F.; BARBEDO, C.J. Tolerância à dessecação de sementes de espécies de Eugenia. Pesquisa Agropecuária Brasileira, Brasília, v.42, n.2, p.265-272, 2007.
FARRANT, J.M.; PAMMENTER, N.W.; BERJAK, P. Recalcitrance - a current assessment. Seed Science and Technology, Zurich, v.16, n.1, p.155-166, 1988.

FERREIRA, S.A.N.; GENTIL, D.F.O.Armazenamento de sementes de camu-camu (Myrciaria dubia) com diferentes graus de umidade e temperaturas. Revista Brasileira de Fruticultura, Jaboticabal, v.25, n.3, p.440-442, 2003.

FU, J.R.; ZHANG, B.Z.; WANG, X.P.; QIAO, Y.Z.; HUANG, X.L. Physiological studies on desiccation, wet storage and cryopreservation of recalcitrant seeds of three fruit species and their excised embryonic axes. Seed Science and Tecnology, Zurich, v.18,n.3 p.743-754, 1990.

GENTIL, D.F.O.; FERREIRA, S.A.N. Viabilidade e superação da dormência em sementes de araçá-boi (Eugenia stipitata ssp. sororia). Acta Amazonica, Manaus, v.29, n.1, p.21-31, 1999.

HONG, T.D.; ELLIS, R.M. Optimum air-dry seed storage enviroments for arábica cofee. Seed Science and Tecnology, Zürich, v.20, n.3, p.547-560, 1992.

KOHAMA, S.; MALUF, A.M.; BILIA, D.A.C.; BARBEDO, C.J. Secagem e armazenamento de sementes de Eugenia brasiliensis Lam. (grumixameira). Revista Brasileira de Sementes, Pelotas, v.28, n.1, p.72-78, 2006.

LABOURIAU, L.G. A germinação das sementes. Washington: Secretaria da OEA, 1983. 173p.

LABOURIAU, L.G.; VALADARES, M.E.B. On the germination of seeds of Calotropis procera (Ait) Ait. f. Anais da Academia Brasileira de Ciências, Rio de Janeiro, v.48, n.2, p.236-284, 1976.

LEPRINCE, O.; HENDRY, G.A.F.; McKERSIE, B.D. The mechanisms of desiccation tolerance in developing seeds. Seed Science Research, Wallingford, v.3, n.3, p.231-246, 1993.

LORENZI, H. Árvores brasileiras: manual de identificação e cultivo de plantas arbóreas do Brasil. 4.ed. Nova Odessa: Instituto Plantarum, 2002. v.1, 368p.

MAGUIRE, J.D. Speed of germination: aid in selection and evaluation for seedling emergence and vigour. Crop Science, Madison, v.2, n.2, p.176-177, 1962.

MALUF, A.M.; BILIA, D.A.C.; BARBEDO, C.J. Drying and storage of Eugenia involucrata DC. seeds. Scientia Agricola, Piracicaba, v.60, n.3, p.471-475, 2003.

MARCOS FILHO, J. Fisiologia de sementes de plantas cultivadas. Piracicaba: FEALQ, 2005. 495p.

MARTINS, C.C.; NAKAGAWA, J.; BOVI, M.L.A. Tolerância à dessecação de sementes de palmito-vermelho (Euterpe 
espiritosantensis Fernandes). Revista Brasileira de Botânica, Brasília, v.22, n.3, p.391-396, 1999.

MELCHIOR, S.J.; CUSTÓDIO, C.C.; MARQUES, T.A.; MACHADO NETO, N.B. Colheita e armazenamento de sementes de gabiroba (Campomanesia adamantium Camb. - Myrtaceae) e implicações na germinação. Revista Brasileira de Sementes, Pelotas, v.28, n.3, p.141-150, 2006.

NAKAGAWA, J. Testes de vigor baseados no desempenho das plântulas. In: KRZYZANOWSKI, F.C.; VIEIRA, R.D.; FRANÇA NETO, J.B. (Ed.). Vigor de sementes: conceitos e testes. Londrina: ABRATES, 1999.2-21p.

PAMMENTER, N.W.; BERJAK, P. A review of recalcitrant seed physiology in relation to dessication tolerance mechanisms. Seed Science Research, Wallingford, v.9, n.1, p.13-37, 1999.

PAMMENTER, N.W.; GREGGAINS, V.; KIOKO, J..I.; WESLEYSMITH, J.; BERJAK, P.; FINCH-SAVAGE, W.E. Effects of differential drying rates on viability retention of recalcitrant seeds of Ekebergia capensis. Seed Science Research, Wallingford, v.8, n.4, p.463-471, 1998.
PARENTE, T.V.; CARMONA, R. Preservação do poder germinativo de sementes de mangaba (Hancornia speciosa Nees e Mart.) em diferentes meios de armazenamento. Revista Brasileira de Fruticultura, Jaboticabal, v.10, n.3, p.71-76, 1988.

ROBERTS, E.H. Predicting the storage life of seed. Seed Science and Technology, Zurich, v.1, n.3, p.499-514, 1973.

SANTOS, C.M.R; FERREIRA, A.G.; ÁQUILA, M.E.A. Características de frutos e germinação de sementes de seis espécies de Myrtaceae nativas do Rio Grande do Sul. Ciência Florestal, Santa Maria, v.14, n.2, p.13-20, 2004.

SCHMILDT, E.R.; FRONZA, V.; DIAZ, J.L.S.; UNÊDA, S.H.; ALVARENGA, E.M. Comparação de métodos físicos de remoção da sarcotesta e de métodos de secagem de sementes de mamoeiro (Carica papaya L.). Revista Brasileira de Sementes, Pelotas, v.15, n.2, p.147-151, 1993.

VALIO, I.F.M.; FERREIRA, Z.L. Germination of seeds of Myrciaria cauliflora (Mart.) Berg. (Myrthaceae). Revista Brasileira de Fisiologia Vegetal, Brasília, v.4, n.2, p.95-98, 1992.

ZINK, E.; ROCHELLE, L.A. Estudos sobre a conservação de sementes, XI - Cacau. Bragantia, Campinas, v.23, n.11, p.111116, 1994. 